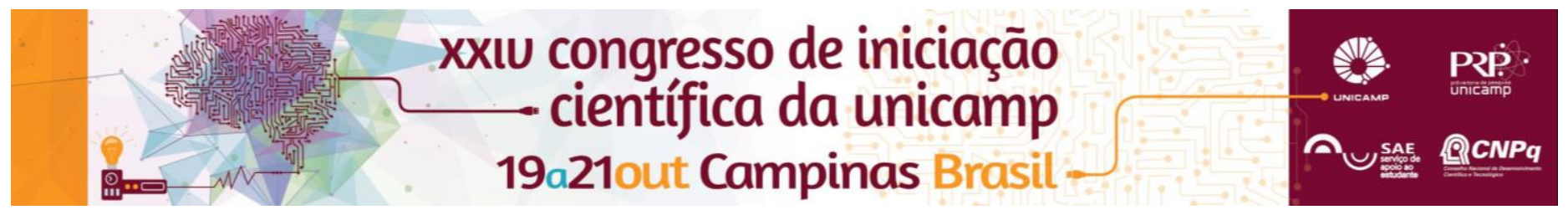

\title{
Sistemas de Gestão da Qualidade na área agrícola de unidades de produção de cana e açúcar e/ou etanol (usinas)
}

\author{
Leonardo das Neves Silva*, Nilson Antonio Modesto Arraes, Luis Ribeiro Vilela Filho
}

\begin{abstract}
Resumo
A presente pesquisa científica se propôs, por meio de revisões bibliográficas, gerar um termo de referência visando à organização de um workshop voltado para a diagnosticação do nível de difusão da gestão da qualidade no setor sucroenergético e do grau de adoção em suas usinas. O termo de referência foi estruturado de modo a apresentar considerações gerais acerca do evento e permitir compreender e contextualizar o tema. O desenvolvimento do mesmo gerou alinhamentos conceituais referentes ao tema e/ou questionamentos que buscam preencher algumas lacunas de pesquisa, os quais posteriormente serão submetidos a especialistas no tema, convidados para o evento organizado.
\end{abstract}

Palavras-chave: usinas, gestão, qualidade

\section{Introdução}

O setor sucroenergético possui grande relevância no cenário agroindustrial mundial, sendo o Brasil o maior produtor de cana de açúcar, com cerca de 630 milhões de toneladas processadas na safra 2014/2015 (90\% do volume sob responsabilidade da região centro-sul) e o segundo maior produtor global de etanol (28 bilhões de litros na safra 2014/2015) (CONAB, 2015).

Segundo Scalco e Toledo (2001), a competitividade e sobrevivência de empresas do segmento agroindustrial dependem da melhoria na qualidade dos produtos oferecidos e da atuação de forma integrada entre os segmentos da cadeia. Essa realidade não é diferente para as unidades produtoras de açúcar e/ou álcool.

Diante da relevância do setor para a economia nacional e da importância da qualidade para suas usinas, motivouse a organização de um workshop cuja finalidade é diagnosticar o nível de difusão da gestão da qualidade (GQ) no setor e o grau de sua adoção nas usinas, bem como avaliar as possibilidades de extrair mais valor desta inovação gerencial.

Para contribuir com sua realização, esta pesquisa teve o objetivo de elaborar o Termo de Referência (TR) do workshop, a partir de revisão bibliográfica.

\section{Resultados e Discussão}

O TR, produto desta pesquisa, visa orientar os convidados sobre sua participação no evento, explicitando as questões que deverão ser exploradas pelos especialistas na organização de suas exposições.

Em um primeiro momento o TR apresenta considerações gerais acerca do evento, tal como os objetivos, informações gerais e estrutura de desenvolvimento do evento. Posteriormente, ele é organizado de modo a explorar a adoção da GQ, o setor sucroenergético e a relação entre eles.

Por meio de revisão bibliográfica, foi conceituado o que é gestão da qualidade, de modo a diferenciar sistemas de gestão e de certificação e apresentar o conceito de TQM (Total Quality Management - Gestão da Qualidade Total) e vincula-lo à concepção de GQ adotada. Nesta conceituação também buscou-se destacar que o nível de abstração adotado foi dos princípios e práticas administrativas da qualidade, em oposição aos métodos, técnicas e ferramentas

Os grandes números do setor sucroenergético são apresentados e os grupos/usinas são classificados por tamanho (moagem total), considerado o mais importante fator a condicionar a difusão e o nível de adoção. Outros fatores são considerados, tais como: tipo de gestão (familiar/empresarial), exigência de mercado (tipo de produto - açúcar, etanol; demanda dos clientes), origem do capital (nacional/misto/estrangeiro), campo de atuação do holding à qual a usina está ligada (exclusivamente agrícola ou não), estratégia de inovação (melhoria ou ruptura).

Para o diagnóstico, os especialistas são convidados a descrevem o processo de implementação e como cada área de abrangência da qualidade (engenharia, controle, garantia e melhoria) vem sendo adotada em cada uma das áreas funcionais das usinas (administrativo, agrícola, indústria e logística). Além disso, eles devem fazer considerações sobre o nível de adoção dos dez princípios da qualidade adota no projeto.

Por fim, os especialistas apresentam as perspectivas e desafios para extrair mais valor da gestão da qualidade nas usinas, bem como avaliam a adequação de algumas ferramentas gerenciais - formulário de auto avaliação, benchmarking setorial e modelo de maturidade.

\section{Conclusões}

O TR permitiu compreender e contextualizar o tema, sendo que todas as etapas no qual está estruturado geram alinhamentos conceituais acerca do tema e/ou questionamentos que buscam preencher lacunas, os quais serão aplicados aos participantes do evento proposto.

\section{Agradecimentos}

Agradecimentos ao $\mathbf{P I B I C / C N P q}$ pelo apoio financeiro a pesquisa científica.

\footnotetext{
${ }^{1}$ Scalco, A.R.; Toledo, J.C. (2001). Gestão da qualidade em cadeias de produção agroindustrial. XXI ENEGEP, 8p.

${ }^{2}$ CONAB (2015). Principais números e crise do setor, Brasília: CONAB. < Disponível em: http://www.unica.com.br/documentos/documentos/. Acessado em: 17 de janeiro de 2016>
} 